\title{
Peertechz
}

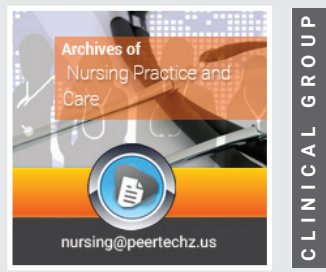

\section{Correlation between job burnout and Fear of COVID-19 among ICU and CCU Nurses (Case study: Shahid Madani Cardiac Hospital, Tabriz, Iran)}

Fatemeh Golabi', Mohammad Bagher Alizadeh Aghdam', Hamed Akbarian $^{1,2 *}$ and Mir Mojtaba Hosseini Mazraehshadi ${ }^{1}$

'Department of Social Sciences, Faculty of Law and Social Sciences, University of Tabriz, Iran

${ }^{2}$ Shahid Madani Cardiac Hospital, Tabriz University of Medical Sciences, Iran
Received: 08 November, 2021

Accepted: 13 December, 2021

Published: 14 December, 2021

*Corresponding author: Hamed Akbarian, Department of Social Sciences, Faculty of Law and Social Sciences, University of Tabriz, Iran, E-mail:

Email: hamedakbarian44@gmail.com

Keywords: Job burnout; Fear of COVID-19; Coronaphobia; ICU and CCU nurses

Copyright: @ 2021 Golabi F, et al. This is an openaccess article distributed under the terms of the Creative Commons Attribution License, which permits unrestricted use, distribution, and reproduction in any medium, provided the original author and source are credited.

https://www.peertechzpublications.com

\section{Check for updates}

\section{Abstract}

Background: Occupational burnout among nurses is one of the major factors which affect the quality of nursing care. Assessing the relationship between burnout and its associated factors is one of the most basic things that should be done so that later, actions can be taken to reduce burnout. Fear of COVID-19 is one of the factors that can increase the burnout of nurses during the Coronavirus Disease 2019(COVID-19) pandemic.

Aim: To investigate the relationship between job burnout and fear of COVID-19 among ICU and CCU nurses.

Methods: The Maslach Burnout Inventory (MBI) and the Fear of COVID-19 Scale (FCV-19S) were distributed to ICU and CCU nurses ( $\mathrm{n}=170)$ at Shahid Madani Cardiac Hospital, Tabriz, Iran, and the correlation between job burnout and fear of COVID-19 was calculated.

Results: The results show that the level of emotional exhaustion and reduced personal accomplishment among participants of this study is average, and depersonalization is at a low level. Also, the level of fear of coronavirus is below average among the respondents. The research showed that emotional exhaustion and fear of COVID-19 were positively correlated $(p<0.05)$, but there was not any significant correlation between depersonalization and fear of Coronavirus; as the relationship between reduced personal accomplishment and fear of COVID-19. In addition, there were significant correlations between age and reduced personal accomplishment, as well as marital status and reduced personal accomplishment $(p<0.05)$. On the other hand, the results showed that there were not any significant correlations between gender and burnout dimensions, nor between educational degree and burnout dimensions.

Conclusion: As job burnout reduces the quality of nursing care, managers must take strategies that reduce job burnout. One of the strategies that they can take is to reduce the fear of COVID-19 by taking wise strategies.

\section{Introduction}

In the 1960 s and 1970s, researchers identified that people whose work involves close involvement with people in need, often in health, social or educational contexts, experienced certain negative feelings about themselves and their clients $[1,2]$.

Job-related burnout has been conceptualized in a variety of ways since appearing in the literature. The term burnout was first used in the 1960s to describe the ill effects of chronic drug abuse, and Freudenberger [3] later used the term to describe a group of co-workers appearing to be psychologically impacted by their negative work experiences. Freudenberger [3] notes that at the beginning of the assignment, these individuals were very idealistic, dedicated to their work, and extremely committed to serving the needs of the client. Within a short period of time, these same individuals demonstrated an increased level of exhaustion, exhibited signs of depression, and seemed to display a less caring attitude toward the clients. As time passed, 
these symptoms worsened, became more pronounced, and were associated with feelings of guilt and diminished self-esteem. However, Freudenberger's initial conceptualization of burnout focused primarily on the characteristics of individuals prone to burnout. These characterizations included behaviors such as being very dedicated and committed to the clients, working many long hours for very little financial compensation, and ignoring their own needs for the benefit of the job. Additionally, these employees took very few vacations and replaced their social lives with time spent on the job.

Veninga and Spradley [4] believed that burnout occurred in the form of four distinct stages: 1) Honeymoon stage; This stage is characterized by the feelings of excitement, enthusiasm, pride, and challenges arising out of the elation about the new job. It gives rise to certain coping mechanisms and strategies, which prove to be dysfunctional later. Also, this euphoria has a flip side it marks the beginning of the depletion of energy. 2) Fuel shortage stage; The general, undefined feelings of fatigue, sleep disturbance, inefficiency, and job dissatisfaction signal future difficulties. These disturbances, in turn, can result in concomitant behaviors of increased eating, drinking, and smoking. 3) Chronic symptom stage; The physiological manifestation that appeared in the previous stage becomes more pronounced and accentuated in this stage and might even lead to the occurrence of symptoms like physical illnesses, anger, irritation, and depression. Crisis stage: Over a period of time, the symptoms may develop into acute psychosomatic disorders like peptic ulcer, tension headache, chronic backache, high blood pressure, sleep disturbance, etc., along with the development of escape mechanisms to deal with the increasing tendencies of self-doubt, a pessimistic view of life, and a general feeling of oppression. 4) Hitting the wall stage; in this stage, there is a total maladaptation due to the failure of the person's coping mechanisms to deal with stress.

Burnout is a concept used to characterize a reaction to long-term stress, which is specifically linked to the emotional strain of working frequently and intensively with other people. Particularly, it seems that professionals working in human services (e.g., nurses, physicians, social workers, and teachers) are vulnerable to burnout [5]. The most widely accepted conceptualization of burnout is found in the work of Maslach and Jackson [5]. They consider burnout as a symptom of emotional exhaustion, depersonalization, and reduced personal accomplishment. Emotional exhaustion refers to a depletion of an individual's emotional resources and the feeling that the individual has nothing left to give to others psychologically. Depersonalization is described in terms of the development of indifferent and negative attitudes towards others. It is assumed that human service professionals distance themselves from the people they work with to cope with their feelings of emotional exhaustion. The third dimension of burnout involves a negative evaluation of personal accomplishments in working with other people. Individuals perceive themselves as being less effective in their job.

\section{Background}

Several systematic reviews and meta-analyses have already shown that nurses present moderate to high levels of burnout syndromes [6-12]. The prevalence of burnout syndromes is different between geographical regions and specialties. In particular, Central Asia and Europe had the lowest burnout symptoms prevalence, while the Sub-Saharan Africa region had the highest $[10,12]$. Also, pediatric, oncology and emergency nurses had the highest burnout symptoms prevalence [11-14] Burnout among nurses is a serious and frequent health issue carrying serious negative implications not only for nurses but also for patients, colleagues, and health care organizations.

One of the emergent global challenges in managing infectious diseases is dealing with the novel coronavirus 2019 (COVID-19). With the extremely high infection rate and relatively high mortality, individuals naturally began worrying about the COVID-19. Indeed, fear of contacting individuals who are possibly infected by COVID-19 has been reported [15]. Unfortunately, fear may amplify the damage of the disease itself. The emergence of the COVID-19 [16,17] and its pandemic nature has exacerbated fears worldwide leading to stigma in some cases [15]. One characteristic nature of infectious disease compared with other conditions is fear. Fear is directly associated with its transmission rate and medium (rapidly and invisibly) as well as its morbidity and mortality. This further leads to other psychosocial challenges including stigmatization, discrimination, and loss [18]. With the high levels of fear, individuals may not think clearly and rationally when reacting to COVID-19.

Nurses play an instrumental role in the health systems response to the COVID-19 pandemic since they are the frontline health care workers directly involved in the treatment and care of patients [19-21]. Nurses are under extreme and persistent psychological pressure since they are particularly exposed to the threat of SARS-CoV-2 infection, and they become overwhelmed by fear for the safety of their health, their close family members, and their patients [22]. Under these circumstances, nurses experience severe psychological and mental problems that could lead to burnout, and then to lower productivity, errors in clinical settings, and lack of concern in handling patients [23-25].

In this research, we investigated the level of job burnout and fear of Coronavirus among ICU and CCU nurses and discovered the correlation between job burnout and fear of COVID-19.

\section{Methods}

\section{Population}

CCU and ICU nurses in Shahid Madani Cardiac Hospital represented the target population for the study. There were 206 CCU and ICU nurses according to the latest statistics provided by the hospital administrators to the researchers.

\section{Sample and Procedure}

A random sampling procedure was used to ensure a sample that resembled the population of CCU and ICU nurses in Shahid Madani Cardiac Hospital. Using the Cochran formula, a sample size of 150 was needed to obtain a sample with an accuracy 
of +5 or -5 percent. An oversampling procedure $(n=170)$ was used to obtain the desired sample. Respondents were evaluated employing anonymous self-reported questionnaires.

\section{Instruments}

In this study, two questionnaires were distributed to the respondents. The questionnaires were the Maslach Burnout Inventory (MBI) and the Fear of COVID-19 Scale (FCV-19S). The Dutch Educators Survey (MBI-NL-ES) version of MBI was adapted from Horn and Schaufeli [26] to assess nurse burnout levels.

Maslach burnout inventory (MBI): The MBI was designed to measure three aspects of job burnout: emotional exhaustion, depersonalization, and personal accomplishment (Maslach C, Jackson SE. Maslach burnout inventory. 1981. California: Palo Alto). [5] The Dutch Educators Survey (MBI-NL-ES) version of MBI was adapted from Horn and Schaufeli [26]. In the American study, scores on the MBI subscales emotional exhaustion, depersonalization, and personal accomplishment are based on the summation of item scores in each subscale. In the MBI-NL-ES the sum score of each subscale is divided by the number of items in that subscale. In the norm tables these mean scale scores are used instead of sum scores since their interpretation is more straightforward (ranging from 0 to 6 ) and because a direct comparison between subscales is then possible [26].

Due to using this questionnaire for assessing the burnout of nurses, in some of the items of this questionnaire the word student has been changed to patient. The questionnaire was translated to Persian and validated to assess the burnout level in nurses. The validity of the MBI-NL-ES questionnaire was $0.87,0.69$, and 0.70 in the emotional exhaustion scale, depersonalization scale, and reduced personal accomplishment scale respectively, measured by the Cronbach's alpha method. The overall Cronbach's alpha coefficient was 0.87 .

Fear of COVID-19 Scale (FCV-19S): The seven-item FCV19S was developed to quickly assess individuals' fear towards COVID-19 [27,28]. A total score is calculated by adding up each item score (ranging from 7 to 35). The higher the score, the greater the fear of coronavirus-19. Responding to items on a five-point Likert scale $(1=$ strongly disagree; $5=$ strongly agree), the FCV-19S is found to be psychometrically sound in assessing fear of COVID-19 in different populations, including different ethnic groups and various vulnerable groups. A higher level of fear toward COVID-19 is indicated by the higher FCV19S score [27].

Social-demographic information: Each respondent was asked to provide their social-demographic information including their gender, age, marital status, and level of education.

\section{Data analysis}

Data was analyzed using SPSS software, version 26 . Different statistical tests (Independent-Samples t-Test, oneway ANOVA, and Pearson's r) were used based on levels of measurement of the variables. A p-value less than 0.05 was considered statistically significant.

\section{Results}

\section{Sample statistics}

In the current study, 151 of the respondents were female, and 19 were male. Most of the participants were married (75.1\%). The mean age was 37.39 years with a standard deviation of 7.46. In addition, 157 respondents had bachelor's degrees and 13 of them had master's degrees or more.
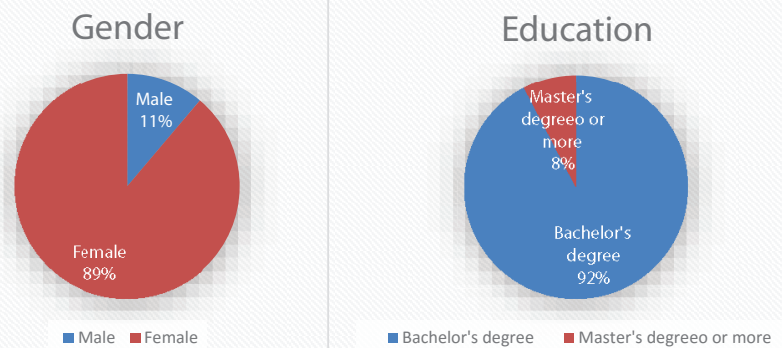

\section{Job burnout}

The normative scores presented in the present study are based on a more refined classification using five percentile ranges (5th, 25th, 75th, and 95th percentile) [26]. In this study, the burnout reports ranged from 0 to 6 for each of the dimensions. The results of the research show that the majority of the respondents had an average level of emotional exhaustion, a low level of depersonalization, and an average level of reduced personal accomplishment. The mean emotional exhaustion, depersonalization, and reduced personal accomplishment were $2.65 \pm 1.28,1.26 \pm 0.87$, and $1.74 \pm 0.84$, respectively. Aggregated answers to the job burnout scales are summarized in Table 1.

\section{Fear of COVID-19 (FCV-19S)}

The score of the fear of COVID-19 among nurses is shown

Table 1: Scores of different dimensions of job burnout among nurses.

\begin{tabular}{|c|c|c|c|}
\hline Burnout dimension & Risk level & $\begin{array}{c}\text { Frequency } \\
\text { (Percentage) }\end{array}$ & Mean \pm SD \\
\hline \multirow{5}{*}{ Emotional exhaustion } & Very low & $3(1.8 \%)$ & \multirow{5}{*}{$2.65 \pm 1.28$} \\
\hline & Low & $29(17 \%)$ & \\
\hline & Average & $122(71.8 \%)$ & \\
\hline & High & $14(8.2 \%)$ & \\
\hline & Very high & $2(1.2 \%)$ & \\
\hline \multirow{5}{*}{ Depersonalization } & Very low & $14(8.2 \%)$ & \multirow{5}{*}{$1.26 \pm 0.87$} \\
\hline & Low & $104(61.2 \%)$ & \\
\hline & Average & $52(30.6 \%)$ & \\
\hline & High & - & \\
\hline & Very high & - & \\
\hline \multirow{5}{*}{$\begin{array}{l}\text { Reduced personal } \\
\text { accomplishment }\end{array}$} & Very low & $3(1.8 \%)$ & \multirow{5}{*}{$1.74 \pm 0.84$} \\
\hline & Low & $71(41.7 \%)$ & \\
\hline & Average & $96(56.5 \%)$ & \\
\hline & High & - & \\
\hline & Very high & - & \\
\hline
\end{tabular}

Citation: Golabi F, Alizadeh Aghdam MB, Akbarian H, Hosseini Mazraehshadi MM (2021) Correlation between job burnout and Fear of COVID-19 among ICU and CCU Nurses (Case study: Shahid Madani Cardiac Hospital, Tabriz, Iran). Arch Nurs Pract Care 7(1): 024-028. DOI: https://dx.doi.org/10.17352/anpc.000057 
in Table 2. According to this table, the level of fear of COVID-19 among respondents of this research was less than average.

\section{Correlation between demographic variables and job bur- nout}

Table 3 describes the significance of the correlations between demographical variables of the study and job burnout. According to the table, there was not a significant correlation between gender and dimensions of burnout; nor between educational degree and burnout dimensions. There was a significant relationship between age and reduced personal accomplishment (correlation coefficient $=(-0.296), \mathrm{p}=0.00)$; so that, as respondents got older, their accomplishments increase. In addition, there was a significant correlation between marital status and reduced personal accomplishment $(\mathrm{F}=3.21, \mathrm{p}=0.04)$; so that, married participants had more personal accomplishment than single ones.

\section{Correlation between job burnout and fear of COVID-19}

Pearson correlation was computed to see the association between job burnout and fear of COVID-19 (Table 4). According to this table, there was a significant correlation between fear of COVID-19 and emotional exhaustion; so that, as fear of COVID-19 increases, the emotional exhaustion increases too, and vice versa. On the other hand, there was not a significant relationship between fear of COVID-19 and depersonalization; nor between fear of COVID-19 and reduced personal accomplishment.

\section{Discussion}

\section{Job burnout}

The results of this cross-sectional study indicate a moderate prevalence of emotional exhaustion and reduced personal accomplishment and a low level of depersonalization among

Table 2: Score of fear of COVID-19 among nurses.

\begin{tabular}{|c|c|c|}
\hline Variable & Mean & Standard Deviation \\
\hline Fear of COVID-19 & 17.28 & 7.10 \\
\hline
\end{tabular}

Table 3: Significance of the correlations between demographic variables and burnout dimensions.

\begin{tabular}{|c|c|c|c|}
\hline Variable & $\begin{array}{c}\text { Emotional } \\
\text { exhaustion }\end{array}$ & Depersonalization & $\begin{array}{c}\text { Reduced personal } \\
\text { accomplishment }\end{array}$ \\
\hline Gender & 0.06 & 0.51 & 0.85 \\
\hline Age & 0.10 & 0.06 & $0.00 * \star$ \\
\hline Marital status & 0.55 & 0.30 & $0.00^{\star}$ \\
\hline Educational degree & 0.57 & 0.56 & 0.48 \\
\hline$* \star p<0.01 ; * p<0.05$. & & & \\
\hline
\end{tabular}

Table 4: Correlation between fear of COVID-19 and dimensions of burnout.

\begin{tabular}{|l|c|c|c|}
\hline $\begin{array}{c}\text { Independent } \\
\text { variable }\end{array}$ & $\begin{array}{c}\text { Emotional } \\
\text { exhaustion }\end{array}$ & depersonalization & $\begin{array}{c}\text { Reduced personal } \\
\text { accomplishment }\end{array}$ \\
\hline Fear of COVID-19 & $0 / 166^{*}$ & 0.138 & 0.079 \\
\hline${ }^{*} \mathrm{p}<0.05$. & & & \\
\hline
\end{tabular}

ICU and CCU nurses in Shahid Madani Cardiac Hospital of Tabriz. The prevalence of burnout dimensions among respondents of this study was similar to those of Altun [29]. In comparison, Torun and Cavusoglu [30] and Cishahayo, et al. [31] reported high levels of emotional exhaustion, depersonalization, and reduced personal accomplishment among nurses.

\section{Fear of COVID-19}

The mean score of fear of COVID-19 among ICU and CCU nurses was low to moderate. In contrary to findings of this study, Hu, et al. [19] reported high levels of fear of COVID-19 among frontline nurses in Wuhan, China.

\section{Correlation between job burnout and fear of COVID-19}

In this study, there was a positive correlation between emotional exhaustion and fear of COVID-19. On the other hand, there was not a significant correlation between depersonalization and fear of COVID-19 and between low personal accomplishment and fear of COVID-19 (Table 4). Because the fear of COVID-19 is an emerging issue, no study has been conducted on the relationship between fear of COVID-19 and burnout among nurses before. While Abdelghani, et al. [32] investigated the relationship between perceived fear of COVID-19 and burnout in Egyptian physicians and according to their findings, the perceived fear of COVID-19 was positively correlated with emotional exhaustion, depersonalization, and low personal accomplishment.

\section{Limitations}

One of the limitations of this study was that all respondents were recruited from a single cardiac hospital. In future researches, the target population of the studies can be greater.

\section{Implications and recommendations}

Since this study has reported a significant relationship between fear of COVID-19 and emotional exhaustion, it is recommended that to reduce the incidence of coronavirus disease and decrease the fear of it among nurses, the process of vaccinating people must be accelerated. Also, the managers should take wise strategies to reduce burnout levels among ICU and CCU nurses.

Another finding of this study was that the prevalence of low personal accomplishment was higher among younger nurses. According to this finding, it is recommended that newly graduated nurses should be supported by senior nurses and administration.

\section{References}

1. Ryan W (1971) Blaming the Victim: Pantheon Books. Link: https://bit.ly/3GIrgf6

2. Wills TA (1978) Perceptions of clients by professional helpers. Psychological Bulletin 85: 968-1000. Link: https://bit.ly/3DQHSzx

3. Freudenberger HJ (1975) The staff burn-out syndrome in alternative institutions. Psychotherapy: Theory, Research \& Practice 12: 73-82. Link: https://doi.org/10.1037/h0086411 
4. Veninga RL, Spradley JP (1981) The work stress connection: How to cope with job burnout. Boston: Little, Brown and Company. Link: https://bit.ly/3EPgRhc

5. Maslach C, Jackson SE (1981) The measurement of experienced burnout. Journal of Organizational Behavior 2: 99-113. Link: https://bit.ly/3oR1CyE

6. Adriaenssens J, De Gucht V, Maes S (2015) Determinants and prevalence of burnout in emergency nurses: a systematic review of 25 years of research. Int J Nurs Stud 52: 649-661. Link: https://bit.ly/3GLqz4V

7. De la Fuente-Solana El, Suleiman-Martos N, Pradas-Hernández L, Gomez Urquiza JL, Cañadas-De la Fuente GA, et al. (2019) Prevalence, Related Factors and Levels of Burnout Syndrome Among Nurses Working in Gynecology and Obstetrics Services: A Systematic Review and Meta-Analysis. International Journal of Environmental Research and Public Health 16: 2585. Link: https://bit.ly/3yqbEKc

8. Gómez-Urquiza JL, Aneas-López AB, Fuente-Solana El, Albendín-García L, Díaz-Rodríguez L, et al. (2016) Prevalence, Risk Factors, and Levels of Burnout Among Oncology Nurses: A Systematic Review. Oncol Nurs Forum 43: E104E120. Link: https://bit.ly/30rjd76

9. López-López IM, Gómez-Urquiza JL, Cañadas GR, De la Fuente El, AlbendínGarcía L, et al. (2019) Prevalence of burnout in mental health nurses and related factors: a systematic review and meta-analysis. International Journal of Mental Health Nursing 28: 1035-1044. Link: https://bit.ly/31Zsl38

10. Owuor RA, Mutungi K, Anyango R, Mwita CC (2020) Prevalence of burnout among nurses in sub-Saharan Africa: a systematic review. JBI Evidence Synthesis 18: 1189-1207. Link: https://bit.ly/3DSR2M1

11. Pradas-Hernández L, Ariza T, Gómez-Urquiza JL, Albendín-García L, De la Fuente El, et al. (2018) Prevalence of burnout in paediatric nurses: A systematic review and meta-analysis. PLoS One 13: e0195039. Link: https://bit.ly/3yq49mT

12. Woo T, Ho R, Tang A, Tam W (2020) Global prevalence of burnout symptoms among nurses: A systematic review and meta-analysis. Journal of Psychiatric Research 123: 9-20. Link: https://bit.ly/3oR1MpK

13. Gómez-Urquiza JL, De la Fuente-Solana El, Albendín-García L, Vargas-Pecino C, Ortega-Campos EM, et al. (2017) Prevalence of Burnout Syndrome in Emergency Nurses: A Meta-Analysis. Critical Care Nurse 37: e1-e9. Link: https://bit.ly/3GGPmH5

14. Parola V, Coelho A, Cardoso D, Sandgren A, Apóstolo J (2017) Prevalence of burnout in health professionals working in palliative care: a systematic review. JBI Evidence Synthesis 15. Link: https://bit.ly/3GLqGgR

15. Lin CY (2020) Social reaction toward the 2019 novel coronavirus (COVID-19). Social Health and Behavior 3: 1. Link: https://bit.ly/3IZicon

16. Guan WJ, Ni ZY, Hu Y, Liang WH, Ou CQ, et al. (2020) Clinical Characteristics of Coronavirus Disease 2019 in China. New England Journal of Medicine 382: 1708-1720. Link: https://bit.ly/3FODqzO

17. Huang C, Wang Y, Li X, Ren L, Zhao J, et al. (2020) Clinical features of patients infected with 2019 novel coronavirus in Wuhan, China. The Lancet 395: 497506. Link: https://bit.ly/3ESNhYf

18. Pappas G, Kiriaze IJ, Giannakis P, Falagas ME (2009) Psychosocial consequences of infectious diseases. Clin Microbiol Infect 15: 743-747. Link: https://bit.ly/33mwKxL
19. Hu D, Kong Y, Li W, Han Q, Zhang X, et al. (2020) Frontline nurses' burnout, anxiety, depression, and fear statuses and their associated factors during the COVID-19 outbreak in Wuhan, China: A large-scale cross-sectional study. EClinicalMedicine 24: 100424. Link: https://bit.ly/3F5EFxi

20. Liu Q, Shen D, Chen S, Liu J (2020) Supporting Frontline Nurses During the Fight Against COVID-19. J Am Psychiatr Nurses Assoc 26: 525-526. Link: https://bit.ly/3dL4fMi

21. Zhan Y, Ma S, Jian X, Cao Y, Zhan X (2020) The Current Situation and Influencing Factors of Job Stress Among Frontline Nurses Assisting in Wuhan in Fighting COVID-19. Frontiers in Public Health 8. Link: https://bit.ly/3s06i7z

22. Joo JY, Liu MF (2021) Nurses' barriers to caring for patients with COVID-19: a qualitative systematic review. International Nursing Review 68: 202-213. Link: https://bit.ly/325sEcY

23. Al Maqbali M, Al Sinani M, Al-Lenjawi B (2021) Prevalence of stress, depression anxiety and sleep disturbance among nurses during the COVID-19 pandemic: A systematic review and meta-analysis. Journal of Psychosomatic Research 141: 110343. Link: https://bit.ly/3EVxLLh

24. Pappa S, Ntella V, Giannakas T, Giannakoulis VG, Papoutsi E, et al. (2020) Prevalence of depression, anxiety, and insomnia among healthcare workers during the COVID-19 pandemic: A systematic review and meta-analysis. Brain, Behavior, and Immunity 88: 901-907. Link: https://bit.ly/3DPoCIX

25. Salari N, Khazaie H, Hosseinian-Far A, Ghasemi H, Mohammadi M, et al. (2020) The prevalence of sleep disturbances among physicians and nurses facing the COVID-19 patients: a systematic review and meta-analysis. Globalization and Health 16: 92. Link: https://bit.ly/3dMrBkz

26. Horn JE, Schaufeli WB (1998) Maslach Burnout Inventory: The Dutch Educators Survey (MBI-NLES) Psychometric evaluations. Department of Social and Organizational Psychology. Utrecht, Netherlands: Utrecht University. Link: https://bit.ly/3INKSAA

27. Ahorsu DK, Lin CY, Imani V, Saffari M, Griffiths MD, et al. (2020) The Fear of COVID-19 Scale: Development and Initial Validation. International Journal of Mental Health and Addiction. Link: https://bit.ly/3oRNR2V

28. Ahorsu DK, Lin CY, Pakpour AH (2020) The Association Between Health Status and Insomnia, Mental Health, and Preventive Behaviors: The Mediating Role of Fear of COVID-19. Gerontology and Geriatric Medicine 6: 2333721420966081. Link: https://bit.ly/3Glecqk

29. Altun I (2002) Burnout and Nurses' Personal and Professional Values. Nursing Ethics 9: 269-278. Link: https://bit.ly/33stv8a

30. Torun T, Cavusoglu H (2018) Examining Burnout and Job Satisfaction of Nurses Working in Pediatric Units/ Pediatri Kliniklerinde Calisan Hemsirelerde Tukenmislik ve Is Doyumunun Incelenmesi. Journal of Education and Research in Nursing 15: 71. Link: https://bit.ly/3oUcMmc

31. Cishahayo EU, Nankundwa E, Sego R, Bhengu BR (2017) Burnout among nurses working in critical care settings: a case of a selected tertiary hospital in Rwanda. 5: 8. Link: https://bit.ly/33udf6z

32. Abdelghani M, El-Gohary HM, Fouad E, Hassan MS (2020) Addressing the relationship between perceived fear of COVID-19 virus infection and emergence of burnout symptoms in a sample of Egyptian physicians during COVID-19 pandemic: a cross-sectional study. Middle East Current Psychiatry, Ain Shams University 27: 70. Link: https://bit.ly/31YMpmxs

Citation: Golabi F, Alizadeh Aghdam MB, Akbarian H, Hosseini Mazraehshadi MM (2021) Correlation between job burnout and Fear of COVID-19 among ICU and CCU Nurses (Case study: Shahid Madani Cardiac Hospital, Tabriz, Iran). Arch Nurs Pract Care 7(1): 024-028. DOI: https://dx.doi.org/10.17352/anpc.000057 